This is the final peer-reviewed accepted manuscript of:

Cesare Oliviero Rossi, Assunta Spadafora, Bagdat Teltayev, Galiya Izmailova, Yerik Amerbayev, Villiam Bortolotti, Polymer modified bitumen: Rheological properties and structural characterization, Colloids and Surfaces A: Physicochemical and Engineering Aspects, Volume 480, 2015, Pages 390-397, ISSN 0927-7757

The final published version is available online at:

https://doi.org/10.1016/i.colsurfa.2015.02.048

Rights / License:

The terms and conditions for the reuse of this version of the manuscript are specified in the publishing policy. For all terms of use and more information see the publisher's website.

This item was downloaded from IRIS Università di Bologna (https://cris.unibo.it/)

When citing, please refer to the published version. 


\section{Accepted Manuscript}

Title: Polymer Modified Bitumen: Rheological Properties and Structural Characterization

Author: Cesare Oliviero Rossi Assunta Spadafora Bagdat Teltayev Galiya Izmailova Yerik Amerbayev Villiam Bortolotti

PII:

DOI:

Reference: S0927-7757(15)00181-8 http://dx.doi.org/doi:10.1016/j.colsurfa.2015.02.048

To appear in: $\quad$ Colloids and Surfaces A: Physicochem. Eng. Aspects

Received date: $\quad 9-12-2014$

Revised date: 25-2-2015

Accepted date: $\quad 28-2-2015$

Please cite this article as: C.O. Rossi, A. Spadafora, B. Teltayev, G. Izmailova, Y. Amerbayev, V. Bortolotti, Polymer Modified Bitumen: Rheological Properties and Structural Characterization, Colloids and Surfaces A: Physicochemical and Engineering Aspects (2015), http://dx.doi.org/10.1016/j.colsurfa.2015.02.048

This is a PDF file of an unedited manuscript that has been accepted for publication. As a service to our customers we are providing this early version of the manuscript. The manuscript will undergo copyediting, typesetting, and review of the resulting proof before it is published in its final form. Please note that during the production process errors may be discovered which could affect the content, and all legal disclaimers that apply to the journal pertain. 


\section{Highlights}

- We investigate the effects of SBS polymer and PPA on the structure of the bitumen

- We examine changes in structures of the bitumen at different aging steps

- ILT analysis of the NMR echo is one of the most powerful tools for the bitumen structure characterization 


\title{
Polymer Modified Bitumen: Rheological Properties and Structural
}

\section{Characterization}

\author{
Cesare Oliviero Rossi ${ }^{1}$; Assunta Spadafora ${ }^{1}$; Bagdat Teltayev ${ }^{2}$; Galiya Izmailova ${ }^{2}$; Yerik \\ Amerbayev $^{2}$; Villiam Bortolotti ${ }^{3}$ \\ ${ }^{1}$ Department of Chemistry and Chemical technologies, University of Calabria, Via P. Bucci, Cubo 14/D - \\ 87036 Arcavacata, Italy \\ ${ }^{2}$ Kazakhstan Highway Research Institute, Nurpeisova Str.,2A, Almaty, 050061, Kazakhstan. \\ ${ }^{3}$ Department DICAM, University of Bologna, Via Terracini 28, Bologna, Italy \\ *cesare.oliviero@unical.it
}

Corresponding author: cesare.oliviero@unical.it

\begin{abstract}
.
Polymer modified bitumen (PMB) is used extensively in thin asphalt surfacing and seals in order to improve specific performances. However, the performances of PMB are not easy to demonstrate with the conventional methods, such as penetration test, softening point etc. In order to a better evaluation, different characterization methods are needed rather then ordinary empirical rheological tests. This work deals with the characterization of linear copolymer Styrene-Butadiene-Styrene (SBS) and SBS + Polyphosphoric Acid (PPA) modified bitumen by using conventional as well as advanced methods on bitumens at different ageing steps and temperature. Fundamental rheological tests, based on a state of the art dynamic shear rheometer in the temperature range from $-30{ }^{\circ} \mathrm{C}$ to $+160{ }^{\circ} \mathrm{C}$ and advanced ${ }^{1} \mathrm{H}$ Magnetic Resonance Relaxometry analysis to evaluate the effect of modifiers on the bitumen structure, were used. Moreover, morphological analysis by Scanning Electron Microscope (SEM) was performed on neat and modified bitumen and the effect of the filler addition on the supra-molecular organization of the bituminous binder was also investigated.
\end{abstract}

Keywords: Bitumen, Rheology, ILT, Structure, Polymers

\section{Introduction}

Bituminous binders are organic materials whose binding and hardening properties are caused by the temperature-related change of adhesion and cohesion of their molecules [1]. Bitumen is often characterized by its chromatographic fractions, the maltenes (saturates, aromatics and resins) and the asphaltenes, soluble and insoluble in $n$-heptane respectively [2], being commonly modeled as a colloid, with maltenes as the continuous phase and micelles of asphaltenes stabilized by associated resins as the dispersed phase [3]. Composition and the colloidal structure determine its physical and rheological properties [4]. These binders are commonly used in the pavement constructions to meet the raising requirements for durability of the road surface $[5,6]$.

A wide range of viscoelasticity is essential to achieve long-lasting road surface, as it ensures consistency of bitumen's rheological state in extreme service temperatures. Modifiers applied for 
improving bitumen's viscoelasticity are [1]: elastomers, plastomers, synthetic resins, crumb rubber, metal-organic compounds, sulfur, natural asphalts and paraffins. In particular, polyphosphoric acid (PPA) can be used for this purpose.

Currently, the most used modifiers for bitumen performance improvement are long chained hydrocarbon polymers [7]. The physical chemical properties of the polymers modified bitumen (PMB) are dominated by the properties of the base bitumen. Moreover, elastomers increase the elasticity of the bitumen at high temperature and reduce the stiffness at low temperature: both the linear and radial Styrene-Butadiene-Styrene (SBS) copolymers, are the most used. In the bitumen, SBS forms a highly elastic network that disappears above $100^{\circ} \mathrm{C}$ and reforms when cooled.

Addition of PPA to the binder results in an increase of softening point with no effect (or sometimes small decrease) on low-temperature brittleness [8], as PPA does not oxidize asphalt. This leads to an improvement of the maximum service temperature (or useful temperature range). Since 1990s, research on using PPA in conjunction with polymers to improve quality of road bitumens has been conducted. The major benefit of this particular combination is synergistic effect - possible reinforcement of both modificators effects on asphalt. It has been observed for binder elasticity, thermal cracking resistance, and resistance to permanent deformation [9]. Moreover, PPA improves adhesion and may eliminate the need for antistripping agents. In addition, the stability of binder during long-time storage at elevated temperatures is increased. Overall cost of using modified asphalt binders is reduced by using fewer modifiers, possible elimination of antistrips, and energy savings from lowering operating temperatures [9]. Addition of PPA may reduce reaction time with some polymers [8]. Polymers linked with PPA are: SBS [10-13], ethylene vinyl acetate [10, 12,] and ethylene terpolymer [14].

On this background, this paper is focused on the deeper understanding of the behavior of bitumen and the effects of polymer based additives on bituminous systems, in order to correlate the macroscopic properties to the microstructure of the aggregates that constitute the colloidal network. In particular, neat, SBS and SBS+PPA modified bitumens have been investigated by using dynamic rheological tests carried out in linear viscoelastic conditions. The rheological properties were further compared with the results of the empirical methods (ring and ball and penetration depth tests) evidencing the potential failures of both methods and looking for potential parameters able to quantify the relationships between mechanical properties and modifications induced by SBS and SBS+PPA. We further used advanced characterization methods such as Time-Domain Nuclear Magnetic Resonance (TD-NMR) of ${ }^{1} \mathrm{H}$ nuclei, Scanning Electron Microscopy (SEM) and Rheology. 
SEM was used to better investigate the morphological structure of unmodified and modified bitumens. While with TD-NMR, we exploited the spin-spin relaxation time $\left(\mathrm{T}_{2}\right)$ measurement to find the soften point of neat and modified bituminous materials to understand the morphology of the colloidal bitumen. To this purpose, the Inverse Laplace Transform (ILT) of the NMR spin-echo signal decay was used to obtain $\mathrm{T}_{2}$ relaxation time distributions of bitumen both at different temperatures and at aging steps. That provided us indications on the nature of the interaction between additives and the colloidal network. Hence, in the present study, we have quantitatively evaluated the effect of the modifiers combining the results of TD-NMR measurements and bidimensional micro-scale scanning electron microscopy.

\section{Experimental}

\subsection{Chemicals and materials}

The bitumen used in this study has been produced in Kazakhstan and it was supplied by Kazakhstan Highway Research Institute (Almaty, Kazakhstan). It has a 90/130 penetration grade. The bitumen was modified with linear SBS (commercial name, Calprene ${ }^{\circledR} 501$ ) and with PPA. Calprene ${ }^{\circledR} 501$ is a 69/31 Butadiene/Styrene thermoplastic copolymer, polymerized in solution and having a linear structure.

The properties of the polymer are presented in Table $\mathbf{1 .}$

\begin{tabular}{|l|c|c|}
\hline \multicolumn{1}{|c|}{ Polymer Properties } & Value & Test Method \\
\hline $\begin{array}{l}\text { viscosity of Toluene solution at } \\
25 \%\end{array}$ & $5 \mathrm{~Pa} \mathrm{~s}$ & MA 04-3-064 \\
\hline $\begin{array}{l}\text { viscosity of Toluene solution at } \\
5,23 \%\end{array}$ & $13 \mathrm{cSt}$ & MA 04-3-003 \\
\hline Volatile matter & $0.4 \%$ & ASTM D-5668 \\
\hline Hunterlab color & 2 & ASTM D-1925-70 \\
\hline Total styrene (on polymer) & $31 \%$ & ASTM D-5775 \\
\hline Hardness & $76^{\circ}$ Shore A & ASTM D-2240 \\
\hline $\begin{array}{l}\text { Insolubles in toluene, 325 } \\
\text { mesh }\end{array}$ & $<0.1, \%$ & MA 04-3-018 \\
\hline Ashes & $<0.35 \%$ & ASTM D-5669 \\
\hline
\end{tabular}


Table 1: TECHNICAL DATA

Polyphosphoric acid, $83.3 \% \mathrm{P}_{2} \mathrm{O}_{5}$, or otherwise stated $115 \% \mathrm{H}_{3} \mathrm{PO}_{4}$ equivalent [15], has been provided by ICL Performance Product LP (St. Louis, MO, USA).

\subsection{Sample preparation}

The first step was dedicated to prepare the polymer modified bitumen, by using a high shear mixing homogenizer (IKEA model). Firstly, bitumen was heated up to $180 \pm 5^{\circ} \mathrm{C}$ until it flowed fully then a given part of SBS (4\% of the weight of the base bitumen) was gradually added $(5 \mathrm{~g} / \mathrm{min})$ to the melted bitumen under a high-speed shear mixer of 5500 to $6000 \mathrm{r} / \mathrm{min}$. Furthermore, the mixture was stirred by a mechanical stirrer at $180{ }^{\circ} \mathrm{C}$ for 2 hours while the rotation speed of mechanical stirrer was $300 \mathrm{r} / \mathrm{min}$ so that the blends became essentially homogenous. The PPA was added to polymer modified bitumen at a level of $0.2 \%$ by weight at $180{ }^{\circ} \mathrm{C}$. The mixture was heated and maintained at $180{ }^{\circ} \mathrm{C}$ and continuously mixed at 5500 to $6000 \mathrm{r} / \mathrm{min}$ for 30 minutes in a closed beaker to avoid any oxidation process. After mixing, the resulting bitumen was poured into a small sealed can and then stored in a dark chamber thermostated at $25^{\circ} \mathrm{C}$ to retain the obtained morphology.

\subsubsection{Aging}

All samples are exposed to two aging steps:

RTFOT: According to ASTM D2872-04, simulation of bitumen aging was done by Rolling ThinFilm Oven Test (RTFOT). Accordingly, a moving film of bitumen was heated in an oven for 85 $\min$ at $163^{\circ} \mathrm{C}$.

The aging of bitumen was determined from changes in its physical and rheological properties, as measured before and after the oven treatment.

PAV: The pressure ageing vessel (PAV) has been used to simulate in-service ageing of base and modified bitumen after 5 to 10 years. The binder is exposed to high pressure and temperature for 20 hours to simulate the effect of long term oxidative ageing.

The apparatus consists of a stainless steel pressure vessel with encased band heaters and integral pressure and temperature controls. A platinum resistance thermometer measures internal test temperature to $\pm 0.1^{\circ} \mathrm{C}$. Selectable test temperatures (standard $90 / 100 / 110^{\circ} \mathrm{C}$ ) are controlled with a precision of $\pm 0.2^{\circ} \mathrm{C}$. Pressure is monitored by transducer and controlled at $(2.1 \pm 0.1) \mathrm{MPa}$. Temperature and pressure calibration were executed. The procedure was performed according to AASHTO/ASTM T179. 
All the prepared mixtures are listed and labeled in Table 2. Labels indicating the samples will be used throughout the text.

\begin{tabular}{|l|l|l|l|}
\hline & \multicolumn{1}{|c|}{ As made } & \multicolumn{1}{c|}{ RTFOT } & \multicolumn{1}{c|}{ PAV } \\
\hline Base bitumen & Sample A & Sample A' & Sample A' \\
\hline Base bitumen $+4.5 \mathrm{wt} \%$ SBS & Sample B & Sample B' & Sample B” \\
\hline Base bitumen $+4.5 \mathrm{wt} \%$ SBS $+0.2 \mathrm{wt} \%$ PPA & Sample C & Sample C' & Sample C', \\
\hline
\end{tabular}

Table 2: Investigated Samples

\subsubsection{Asphaltenes determination}

Asphaltenes were isolated from bitumens in the manner described elsewhere [16]. A 2-3 g of bitumen was dissolved in a volume (in $\mathrm{ml}$ ) of toluene numerically equal to the weight of the sample. A volume of pentane equal to forty times the toluene was added. The mixture was shaken and then kept in the dark during precipitation for 2 hours with occasional shaking. Asphaltenes were collected on a glass fiber filter, washed with pentane until the filtrate was colorless then dried and weighed. In addition, the asphaltenes received additional "purification" by repetition of the reprecipitation procedure.

\subsection{Empirical Characterization.}

The ring and ball test (ASTM Standard D36) [17] was used to determine the bitumen softening temperature (R\&B T, ring and ball temperature). The test was performed by means of a ring and ball B530 (Tecnotest, Italy) apparatus.

According to the standard procedure (ASTM D946) [17] the bitumen consistency was evaluated by measuring the penetration depth (531/2-T101, Tecnotest, Italy) of a stainless steel needle of standard dimensions under determinate charge conditions (100 g), time (5 s) and temperature (25 $\left.{ }^{\circ} \mathrm{C}\right)$.

\subsection{Rheological characterization}

Dynamic Shear Rheological (DSR) tests on bitumen samples were carried out using a controlled shear stress rheometer (SR5, Rheometric Scientific, USA) equipped with a parallel plate geometry (gap $2 \mathrm{~mm}, \phi=25 \mathrm{~mm}$ within the temperature range $20-150{ }^{\circ} \mathrm{C}$, gap $2 \mathrm{~mm}, \phi=8 \mathrm{~mm}$ within the temperature range from 30 to $\left.-20^{\circ} \mathrm{C}\right)$ and a Peltier system $\left( \pm 0.1^{\circ} \mathrm{C}\right)$ for temperature control.

Dynamic tests, carried out in conditions of linear material behavior where measured material features are independent of the amplitude of applied load and are the only function of 
microstructure [18], were adopted for material characterization. Aimed at investigating the material phase transition, temperature sweep tests were performed at $1 \mathrm{~Hz}$ increasing temperature from -30 ${ }^{\circ} \mathrm{C}$ to $150{ }^{\circ} \mathrm{C}$ (larger final temperatures, up to $150{ }^{\circ} \mathrm{C}$ were adopted for modified bitumens) at 1 ${ }^{\circ} \mathrm{C} /$ min and applying the proper stress values to guarantee linear viscoelastic conditions (previously determined by stress sweep tests) at all tested temperatures.

At low temperature, the rheological tests were carried out with a Dynamic Mechanical Analyzer (DMA, TTDMA, Triton Technology, UK), equipped with a liquid nitrogen cooling system, in a 3Point Bending configuration.

Time cures were carried out at $1 \mathrm{~Hz}$ frequency in linear viscoelastic conditions previously determined by strain sweep tests at different temperatures. The samples were initially kept a $-30{ }^{\circ} \mathrm{C}$ for $4 \mathrm{~min}$, to obtain uniform temperature conditions, and then heated up to $5{ }^{\circ} \mathrm{C}$ with a $1{ }^{\circ} \mathrm{C} / \mathrm{min}$ thermal ramp. During the tests a periodic sinusoidal displacement was applied to the sample and the resulting sinusoidal force was measured in terms of amplitude and phase angle [19].

More details about the mechanical characterization (DSR, DMA) can be found elsewhere [6, 19].

\subsection{NMR measurement and Inverse Laplace Transform (ILT).}

Relaxation experiments were carried out at temperatures ranging from +30 to $+120{ }^{\circ} \mathrm{C}\left( \pm 0.1^{\circ} \mathrm{C}\right)$ by means of a homemade NMR instrument that operates at a proton frequency of $15 \mathrm{MHz}$. In this preliminary work only that measured at $30^{\circ} \mathrm{C}$ is analyzed and shown. In a basic NMR concept, at equilibrium in a steady uniform magnetic field, nuclei having spin are distributed among the energy levels according to a Boltzmann distribution and form a net magnetization vector. The absorption of energy from a radiofrequency pulse, results in a disruption of this distribution. Then when the pulse ceases, the nuclear spin system returns to equilibrium. In this view the transverse component of the magnetization vector, exponentially decays towards its equilibrium. The $T_{2}$ is called the spin-spin relaxation time because the relaxation concerns with the exchange of energy only among spins and not with the surrounding environment.

The $\mathrm{T}_{2}$ decay signal was acquired by means of a CPMG sequence with an interpulse time of $160 \mu \mathrm{s}$. The CPMG signals were composed of 400 echoes, the number of averages was 128 , resulting in a signal-to-noise level of about 500. Usually the $\mathrm{T}_{2}$ relaxation time varies all over the sample because of intrinsic sample heterogeneity, surface relaxation effects and magnetic field inhomogeneities [20]. Therefore, in general the acquired NMR signal is analyzed as a sum of exponential terms. Or, in a more realistic approach, a continuous distribution of relaxation times should be observed [21]. Thus, if inside the sample a continuous distribution of relaxation times exists, the amplitude $A_{n}$ of the $\mathrm{n}^{\text {th }}$ echo in the echo train is given by: 


$$
A_{n}=A_{0} \int_{0}^{\infty} P\left(T_{2}\right) e^{-2 n \tau / T_{2}} d T_{2}
$$

Where $\mathrm{A}_{0}$ is a constant and $\tau$ is the half echo time. $\mathrm{P}\left(\mathrm{T}_{2}\right)$ is the ILT of the unknown function that fit the echo amplitude curve. Hence $\mathrm{P}\left(\mathrm{T}_{2}\right)$ can be understood as a distribution of rate (inverse of time) constants, strictly speaking, a probability density function (PDF) that, among other things, could account for the different macro-structures that compose the bitumen binder [22].

In this work, ILT computation was done by means of UpenWin, a Windows softwere written in $\mathrm{C}++$ and distributed by the University of bologna, that implement the algoritm UPEN [23]. UPEN permits to obtain distributions of relaxation time without multiple peaks not required by the data to be separate, preventing physical misinterpretation of data [24].

\subsection{Morphological analysis}

The bitumen surface was observed by a Scanning Electron Microscope (SEM) (Cambridge Stereoscan 360, Cambridge Instruments, UK). Sample specimens were cryogenically fractured in liquid nitrogen to guarantee a sharp brittle fracture, and were successively sputter coated with a thin gold film prior to SEM observation. The dimensions of the observed peculiarities on the surface were directly read from the SEM image.

\section{RESULTS AND DISCUSSION}

\subsection{Mechanical Behavior}

Firstly, the penetration depth (PN), softening point (R\&B) and the asphaltene content were determined using standardized tests (Table 3).

\begin{tabular}{|l|c|c|c|}
\hline \begin{tabular}{|l|l|} 
Initial state \\
SAMPLE
\end{tabular} & $\begin{array}{c}\mathbf{P N}(\mathbf{m m}) \\
\text { Penetration depth } \\
\pm 1\end{array}$ & $\begin{array}{c}\mathbf{R \& B}\left({ }^{\circ} \mathbf{C}\right) \\
\text { Softening point } \\
\pm 1\end{array}$ & $\begin{array}{c}\mathbf{X}_{\mathbf{A}}(\mathbf{w t} \%) \\
\text { Asphaltene } \\
\text { content } \pm 0.5\end{array}$ \\
\hline Neat bitumen & 104 & 46 & 15,1 \\
\hline SBS bitumen & 52 & 76 & 19,2 \\
\hline SBS +PPA bitumen & 47 & 77 & 19,9 \\
\hline
\end{tabular}

\section{Table 3. Standardized tests.}

Although each bitumen displayed a unique role, a good correlation exists between bitumen hardness and asphaltenes content for each of the investigated bitumen. Several important points can be 
inferred from the data in Table 3. First, as expected, the asphaltenes fraction seems to be the dominant component controlling hardness. Second, the asphaltenes, or at least their effects on hardness, are quite different from fresh bitumen to another one. The asphaltene content was very similar for all doped samples, therefore it increased with the aging step. This could result from differing asphaltenes composition and/or from different solubility or dispersive powers of the maltenes fraction among the different bitumens where the polymer displayed a fundamental role. Obviously, there are effects of polar functionality on oxidative age hardening.

However, the additives allow shifting the viscoelastic-sol transition temperature (TR) at around 40 ${ }^{\circ} \mathrm{C}$ higher than the neat bitumen TR.

Rheology temperature-sweep experiments have been exploited to have some information on the structural changes induced by temperature, trying to better define a TR range. In fact, in this experiment, the evolution of the storage and loss moduli is continuously monitored during a temperature ramp, at a constant heating rate $\left(1^{\circ} \mathrm{C} / \mathrm{min}\right)$ and at a frequency of $1 \mathrm{~Hz}$. In Figure 1 the time cure test of the neat no aged bitumen is shown. At high temperatures the elastic modulus $G^{\prime}(\omega)$ have a non-linear behaviour at around $100^{\circ} \mathrm{C}$. The starting point of the non-linear region of $\mathrm{G}^{\prime}(\omega)$ can be considered as the beginning of the TR region. The whole transition process from viscoelastic to liquid regime ends when $G^{\prime}(\omega)$ modulus is no longer detectable and consequently the loss tangent $\tan \delta$ diverges at about $100^{\circ} \mathrm{C}$.

\section{FIGURE 1}

$\tan \delta$ increases with increasing temperature, evidencing a reduction in material consistency. In fact, the prevalent liquid-like behaviour is enhanced by the temperature increase. Phase angle values at low temperature are quite scattered, owing to instrumental problems related to the high material consistency. Obtained results are in agreement with the typical bitumen temperature behaviour that can be separated into two regions, corresponding to two different rheological relaxation mechanisms [3]:

- At high temperature a transition from a viscoelastic material to a viscous liquid ( $\alpha$-relaxation) can be observed.

- At low temperature a transition from a glassy elastic solid to a viscoelastic liquid ( $\beta$ relaxation) occurs.

The considered experimental data evidence both the $\alpha$ - and $\beta$-relaxations even if the $\beta$-relaxations are more evident from the DMA data (see discussion below). 
The transition temperatures depend on the specific bitumen origin and composition. This rheological behaviour is often described by a colloidal model considering bitumen as a multidisperse micellar system with a rather complicated internal structure based on asphaltenes micelles dispersed within a maltene phase [5]. The $\alpha$-relaxation is attributed to solid phase (asphaltene particles) while the $\beta$-relaxation is mainly attributed to the vitrification of the maltenes, although a coupling between asphaltenes and maltenes affects both transitions.

According to this model the bitumen, from a rheological point of view, could be described as a weak gel made by asphaltene aggregates interacting with each other and entrapping the liquid maltene phase [25]. The specific rheological properties should depend on asphaltene content and particle-particle interactions and on the presence of additives. The TR from a viscoelastic to a viscous behaviour, could be assumed as the value at which loss tangent diverges, even though it could be difficult to estimate exactly this asymptotic value.

In Figure 2 the time cure tests of the samples are shown and some information can be extracted from these plots. The viscoelastic-liquid TR increases with addition of the modifier contents and with the aging process.

\section{FIGURE 2}

The DMA data show that the $\left|E^{*}\right|$ modulus exhibits a plateau at low temperature followed by a decrease with increasing temperature (Figure 3). Moreover, the loss tangent is always lower than unity, confirming a prevalent solid-like behaviour of all materials. According to the literature [3] at low temperature a transition from a viscoelastic liquid to a glassy elastic solid, the $\beta$-relaxation mechanism, occurs.

Effects of low temperature on bitumen properties are typically evidenced by the glass transition temperature, Tg: when temperature is lower than Tg, bitumens are glassy, hard and brittle, whereas for the temperature higher than $\mathrm{Tg}$ viscoelastic liquid-like properties are exhibited. The mechanical glass transition was detected by using DMA data, as the value where loss modulus evidences a peak. The sample without additive shows a TR at almost $-26^{\circ} \mathrm{C}$ and the sample with addition of SBS and PPA shows more than one peak at -19 and $-10.5^{\circ} \mathrm{C}$, as evident from loss tangent curve, probably caused by different colloidal network due to the PPA modifications and proper Tg of the polymer.

Following the initial plateau at low temperature the complex modulus of the two samples decreases with increasing temperature, and a solid to liquid transition can be evidenced by the achievement of 
the unit value of loss value. It is evident the difference of about $6{ }^{\circ} \mathrm{C}$ for the two investigated bitumens.

\section{FIGURE 3}

\subsection{Microstructural Characterization}

As previously stated, the mechanism of chemical modification of bitumen with SBS and PPA is still under investigation and not completely understood, therefore, with the aim of better investigating the microstructural changes, modified and unmodified bitumens were analysed by SEM.

The SEM photographs of the A type bitumens are shown in Figure 4 . For neat bitumens (Figure 4a), the surface shows a network of separated homogeneous and smooth zones probably due to the vacuum experimental conditions.

The sequence of images clearly shows how the microstructure of bitumen is affected by the SBS and PPA. In the SBS modified bitumen the surface is rough, due to the presence of the elastomeric that adsorbs the maltene inducing a difference on the surface. While the presence of PPA creates a sort of protuberances on the rough surface due to the reduction of micellar aggregate size that increases the surface to volume ratio and the solvation phenomena of asphaltenes [2]

Elementary analysis by Energy Dispersive Spectroscopy, carried out on the samples, has shown no phosphorous compound in asphaltene domains of unmodified bitumen, while phosphorous compounds are present in asphaltene domains from PPA modified bitumen confirming the PPA effects on the formation of asphaltene.

\section{FIGURE 4}

\subsection{NMR study}

We also have performed the ILT analysis of the NMR echo signal decay in order to obtain the $\mathrm{T}_{2}$ relaxation time distributions. As previously mentioned, this technique allows finding the PDF distribution associate to different relaxation times that correspond to different molecular aggregates inside the samples. Results are shown in Figure 5, where are plotted the distributions PDF as a function of the relaxation times. Shorter $T_{2}$ times correspond to more rigid supra-molecular aggregates, hence they was attributed to asphaltenes, while longer $T_{2}$ times to the more mobile maltene fraction. In table 4 some peaks position obtained from distributions of figure 5 are showed. The $T_{2}$ relaxation time distribution for the neat bitumen presents two peaks (Figure 5a). The peak that falls above $0.3 \mathrm{~ms}$ is due to asphaltene fraction; the one centred near at $1 \mathrm{~ms}$ corresponds to maltene. The ILT of the aged bitumen presents again two peaks, which however are shifted toward 
shorter times. For asphaltene the variation, from sample A to A', was about of a $13 \%$ (with a stronger effect, more the aging step is increased), whereas for maltene the variation is more significant, about a $20 \%$. This probably indicates a gradually increase of the materials rigidity, increased viscosity, with the on-going of the oxidation process. It is interesting the effect of SBS as antiaging agent. Figure $5 \mathrm{~b}$ shows that aging steps do not substantially affect the peaks position, especially for the asphaltene peaks. These results were already previously remarked when has been discussed the curve test results.

In the samples where the PPA is present (Figure 5c), times distribution are a bit scattered, and basically shifted forward shorter times, especially the asphaltene picks. Therefore, for example, passing from sample A to $\mathrm{C}$, the maltene peak shifts of about $35 \%$, whereas the asphaltene peaks of about $45 \%$. This behavior is probably mainly due to a reduction of micellar aggregate sizes that entail an increases of viscosity of the colloid. The effect of SSB seems negligible on maltene behavior.

\section{FIGURE 5}

\begin{tabular}{|c|c|c|}
\hline SAM PLE & $\begin{array}{c}\text { Asphaltene } \mathrm{T}_{\mathbf{2}} \text { peak position } \\
(\mathbf{m s}) \pm \mathbf{0 . 0 1}\end{array}$ & $\begin{array}{c}\text { Maltene } \mathrm{T}_{\mathbf{2}} \text { peak position } \\
\text { (ms) } \pm \mathbf{0 . 0 1}\end{array}$ \\
\hline $\mathrm{A}$ & 0.38 & 0.92 \\
\hline $\mathrm{A}^{\prime}$ & 0.35 & 0.69 \\
\hline $\mathrm{A}^{\prime \prime}$ & 0.33 & 0.73 \\
\hline $\mathrm{B}$ & 0.24 & 0.90 \\
\hline $\mathrm{C}$ & 0.21 & 0.60 \\
\hline
\end{tabular}

Table 4. Peaks position from calculated ILT distributions.

\subsection{Overview}

The hard consistency of the samples is strongly affected by aging processes. This is due to the oxidized aged bitumen. During the oxidative aging, the concentration of polar functional groups becomes sufficiently high to immobilize an excessive number of molecules through intermolecular association, the molecules or molecular agglomerates lose sufficient mobility to flow past one another under thermal or mechanical stress. The resulting embrittlement of the asphalt makes it susceptible to fracturing or cracking and resistant to healing. Hence, the penetration depth decreases according to the additives content and the aging steps, while on the contrary, the softening points 
increase. Also the viscoelastic-liquid TR increase with addition of the modifier contents and with the aging process.

At low temperature the modified bitumens are more solid then the neat bitumen at the initial state (no aging), while after the aging processes (both RTFOT and RTFOT +PAV) all samples present similar values of $\tan \delta$.

This is an important experimental result because it evidences the antiaging effect of SBS modifier, that could be due to the capacity of the polymer to absorb the maltene and consequently protects it against oxidation process.

When the effects of PPA addition on bitumen are considered, an increase in the solid-like behaviour with PPA content is observed, in agreement with previous literature works[2]. In fact, the PPA effect is mainly due to the reduction of micellar aggregate size increasing the surface to volume ratio and the solvation phenomena. At low temperature the effect of PPA is less evident, in fact polymers doped bitumens show similar $\tan \delta$ values. The SBS polymer effect covers the PPA effects.

Microstructure of bitumen is affected by the SBS and PPA where the SBS modified bitumen surface is rough and PPA creates protuberances on the surface.

For the sample C', which contains PPA, we have registered the largest TR deviation from the neat bitumen. Indeed, the sample turned from gel to liquid phase at a temperature over $125^{\circ} \mathrm{C}$. Also, in this case the TR observed by TD-NMR analysis is similar to that determined by rheological measurements.

However, we can make some new and interesting considerations. By TD-NMR distributions (Figure 5), only two peaks are found, similarly for the neat, SBS and SSB+PPA modified bitumens. In addition, for the bitumen added with PPA, we observed that the $T_{2}$ peaks have wider areas and are centred to a shorter time than the correspondent peaks for the neat and SBS modified bitumens. As shown by SEM images, this could be explained by the more fragmented and heterogeneous structure of samples.

\section{Conclusions.}

In this paper the effects of SBS and PPA modifier as well as the aging process on the microstructure of the bitumen were investigated using different chemical physic techniques.

In particular, the ILT analysis of the NMR signal decay was showed to be one of the most powerful tools useful for the bitumen structure characterization due to its non-destructive nature and ability to follow the structural evolution of the colloidal bitumen system. 
As far as we know, for the first time the rheological behaviour of the SBS + PPA modified bitumen was deeply investigated and it was elucidated the anti-aging affect of the SBS modifier due to the capacity of the polymer to absorb the maltene and consequently to protect it against oxidation processes.

An increase in the solid-like behaviour with PPA content was observed in both higher TR temperatures and TD-NMR analysis. The PPA effect is mainly due to the reduction of micellar aggregate sizes. At low temperatures, the effect of PPA is less evident, the polymer doped bitumens show similar $\tan \delta$ values and the SBS polymer effect covers the PPA effects.

\section{Acknowledgment}

This work has been partially supported by the European Commission, the European Social Fund and the Calabria Region. The authors are solely responsible for the content of this paper and the European Commission and Calabria Region disclaim any responsibility for the use that may be made of the information contained therein.

\section{References}

[1] R. Karlsson, U. Isacsson Material Related Aspects of Asphalt Recycling:State of the Art. J. Mater. Civ. Eng., 18 (2006) 81.

[2] F.L. Roberts, P.S. Kandhal, E.R. Brown, D.Y. Lee, T.W. Kennedy Hot Mix Asphalt Materials, Mixture Design And Construction. Second Edition, National Asphalt Pavement Association Research and Education Foundation: 5100 Forbes Boulevard Lanham, MD 20706-4413 USA, 1996

[3] J. Ph. Pfeiffer, R. N. J. Saal Asphaltic Bitumen as Colloid System J. Phys. Chem., 44 (1940) 139-149.

[4] I. Gaweł, M. Kalabińska, J. Piłat Asfalty drogowe. Wydawnictwa Komunikacji i Łączności 2001.

[5] N. Baldino, D. Gabriele, F.R. Lupi, C. Oliviero Rossi, P. Caputo, T. Falvo, T. Rheological effects on bitumen of polyphosphoric acid (PPA) addition Construction and Building Materials, 40 (2013) 397-404.

[6] N. Baldino, D. Gabriele, C. Oliviero Rossi, L. Seta, F.R. Lupi, P. Caputo Low temperature rheology of polyphosphoric acid (PPA) added bitumen Construction and Building Materials, 36 (2012) 592.

[7] T. McNally Polymer Modified Bitumen Properties and Characterisation A volume in Woodhead Publishing Series in Civil and Structural Engineering, Elsevier, (2012).

[8] J. F. Masson, P. Collins, J. R. Woods, S. Bundalo-Perc, J.C. Margeson Chemistry and effects of polyphosphoric acid on the microstructure, molecular mass, glass transition temperatures 
and performance grades of asphalts Journal of the Association of Asphalt Paving Technologists 78 (2009) 403-430.

[9] H. Jaroszek Polyphosphoric acid (PPA) in road asphalts modification CHEMIK 66 (2012) $1340-1345$.

[10] Patent WO 9958600

[11] Patent US 5880185,

[12] Patent US 5070123,

[13]Patent US 5451621

[14] Patent US 6117926

[15] J. F. Masson Brief review of the chemistry of polyphosphoric acid (PPA) and bitumen Energy Fuels 22 (2008) 2637-2640.

[16] K. H. Altgelt, M. M. Boduszynski Composition and Analysis of Heavy Petroleum Fractions, Marcel Dekker Inc., New York (1994).

[17] ASTM International American society for testing and materials. In: Annualbook of ASTM standards, 3rd ed. Philadelphia, (1990).

[18] H. A. Barnes, J. F. Hutton, K. Walters An introduction to rheology. Amsterdam, Elsevier Science, (1989).

[19] F. E. Antunes, L. Gentile, C. Oliviero Rossi, L. Tavano, G. A. Ranieri Gels of Pluronic F127 and nonionic surfactants from rheological characterization to controlled drug permeation Colloids and Surfaces B: Biointerfaces, 87 (2011) 42-48.

[20] H.Y. Carr, E.M. Purcell Effects of Diffusion on Free Precession in Nuclear Magnetic Resonance Experiments Phys. Rev., 94 (1954) 630.

[21] U. Bilardo, G. C. Borgia, V. Bortolotti, P. Fantazzini, E. Mesini Magnetic resonance lifetimes as a bridge between transport and structural properties of natural porous media Journal of Petroleum Science and Engineering, 5 (1991) 273-283.

[22] L. Gentile, L. Filippelli, C. Oliviero Rossi, N. Baldino, G.A. Ranieri Rheological and H-NMR spin-spin relaxation time for the evaluation of the effects of PPA addition on bitumen Mol. Cryst. Liq. Cryst., 558 (2012) 1.

[23] ] V. Bortolotti, R. J. S. Brown, P. Fantazzini UpenWin: a software to invert multi-exponential relaxation decay data. Distributed by the University of Bologna, villiam.bortolotti@unibo.it (2009)

[24] M. Gombia, V. Bortolotti, B. De Carlo, R. Mongiorgi, S. Zanna, and P. Fantazzini Nanopore Structure Buildup during Endodontic Cement Hydration Studied by Time-Domain Nuclear Magnetic Resonance of Lower and Higher Mobility 1H J. Phys. Chem. B, 114 (2010) 17671774. 
[25] I. Nicotera, C. Oliviero, G. A. Ranieri, A. Spadafora, M. Castriota, E. Cazzanelli Temperature evolution of thermoreversible polymer gel electrolytes LiClO4/ethylene carbonate/poly(acrylonitrile) J. Chem. Phys., 117 (2002) 7373.

\section{Figure Captions}

FIGURE 1: Semilog plots of time cure tests at $1 \mathrm{~Hz}$ in the range from -30 to $120^{\circ} \mathrm{C}$ for neat no aged bitumen.

FIGURE 2: Semilog plots of time cure tests at $1 \mathrm{~Hz}$ in the range from -30 to $120^{\circ} \mathrm{C}$ for all of the bitumen samples.

FIGURE 3: Temperature ramp test $(1 \mathrm{~Hz})$ for bitumen: Samples A and C. $\left|E^{*}\right|$ modulus and loss tangent are plotted.

FIGURE 4: SEM images of neat (a), SBS (b), and SBS+PPA (c) bitumens.

FIGURE 5: ILT relaxation time distributions of neat and modified bitumen samples measured at $30{ }^{\circ} \mathrm{C}$ at different aging steps: not aging (A, B, C), RTFOT aging (A', B', C') and PAV aging (A', B', C'). 5a) neat base bitumen; 5b) base bitumen with SBS added; 5c) base bitumen with SBS and PPA added. 


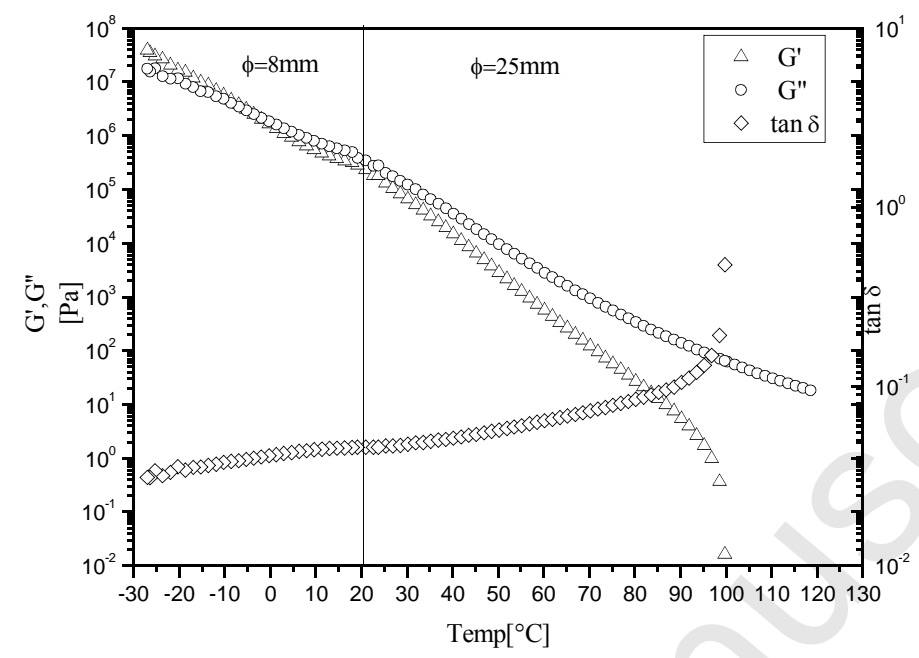

FIGURE 1 

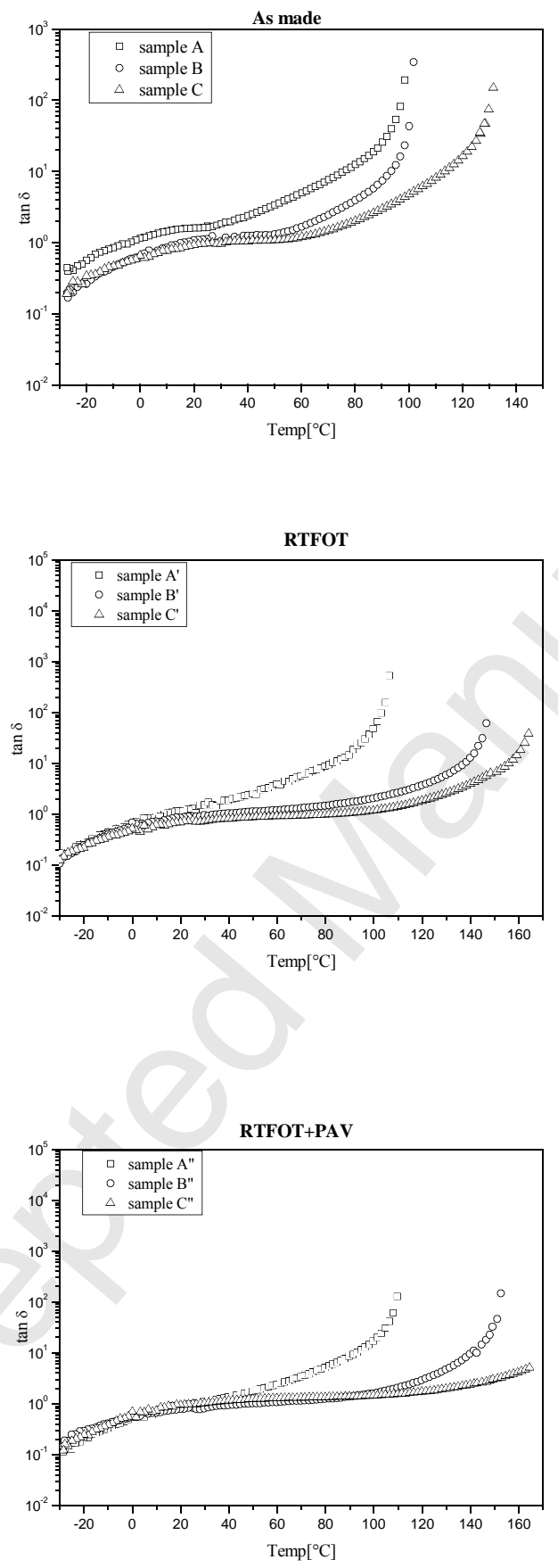

FIGURE 2 

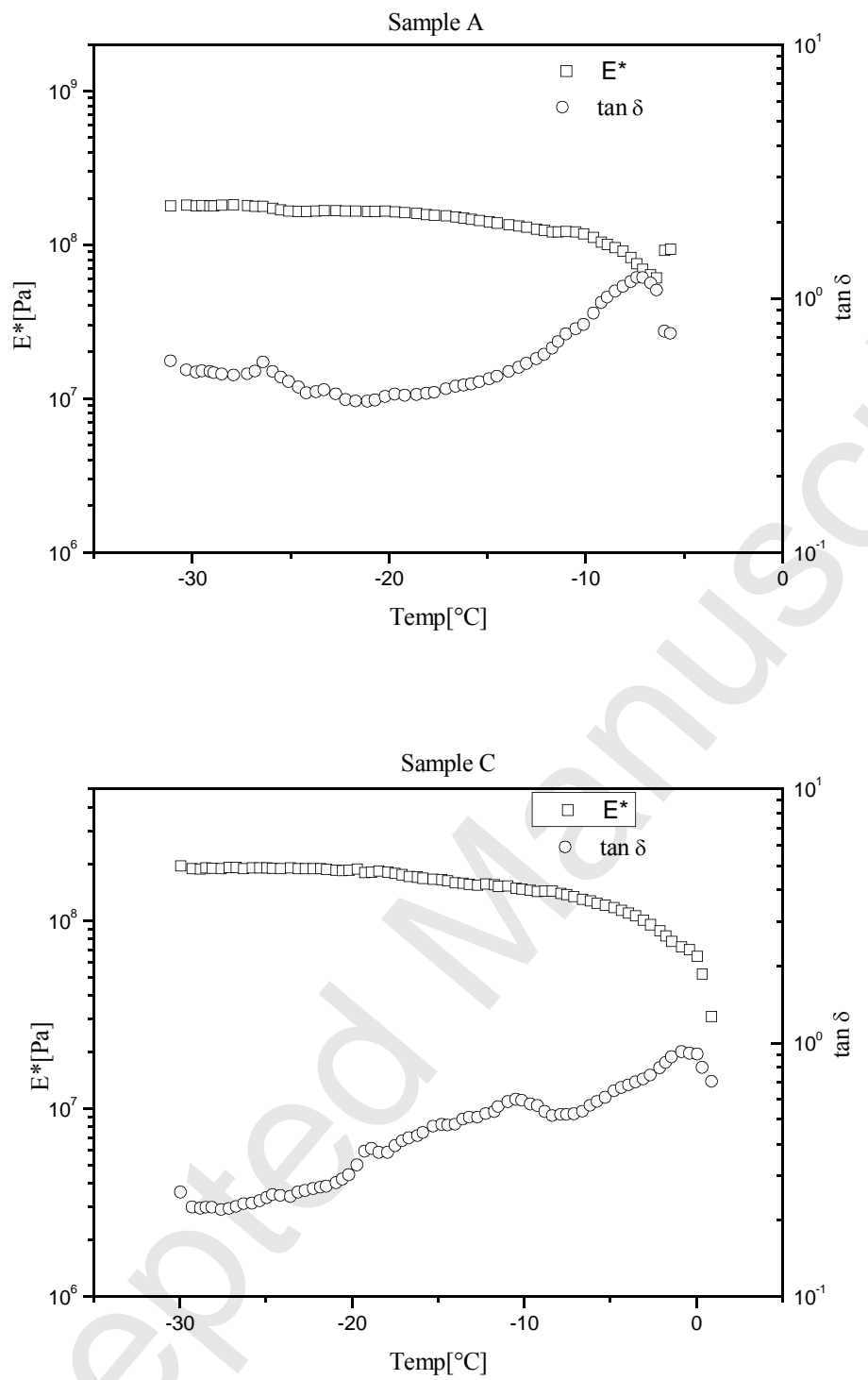

FIGURE 3 


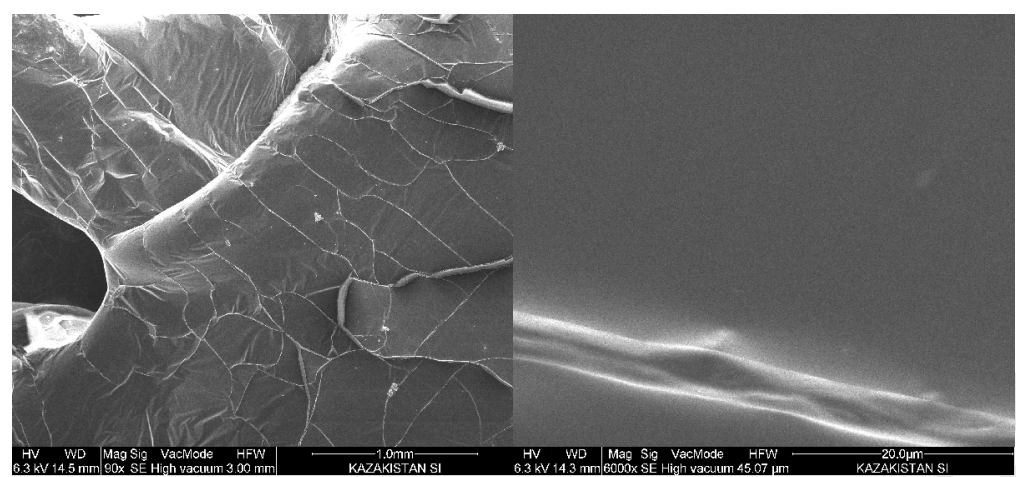

(a)

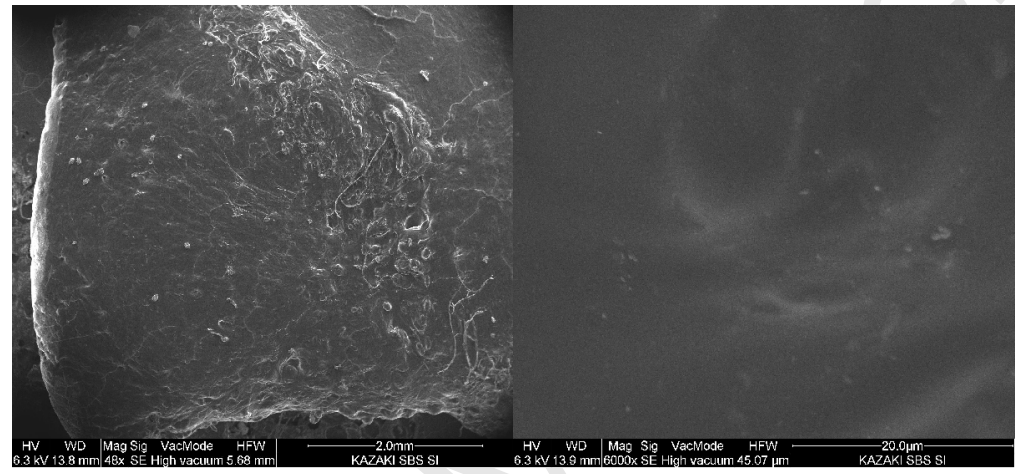

(b)

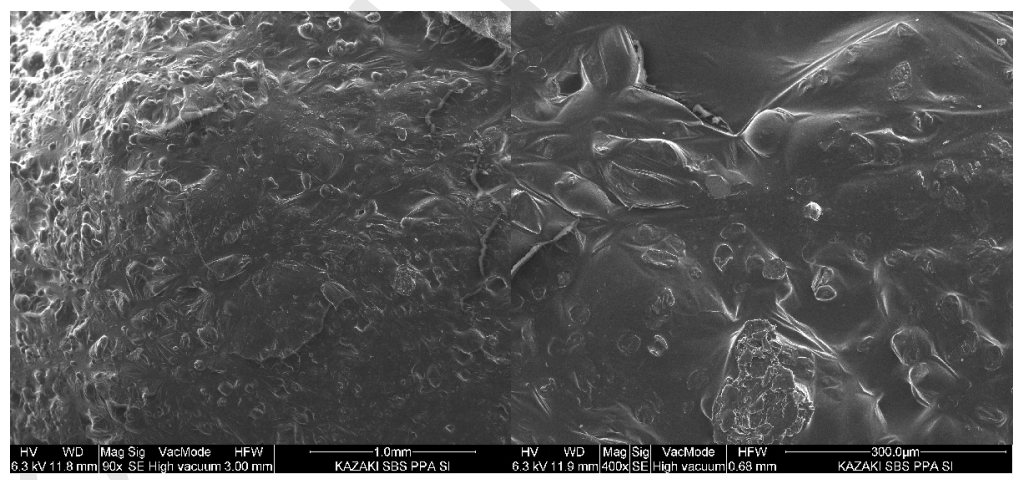

(c)

FIGURE 4 


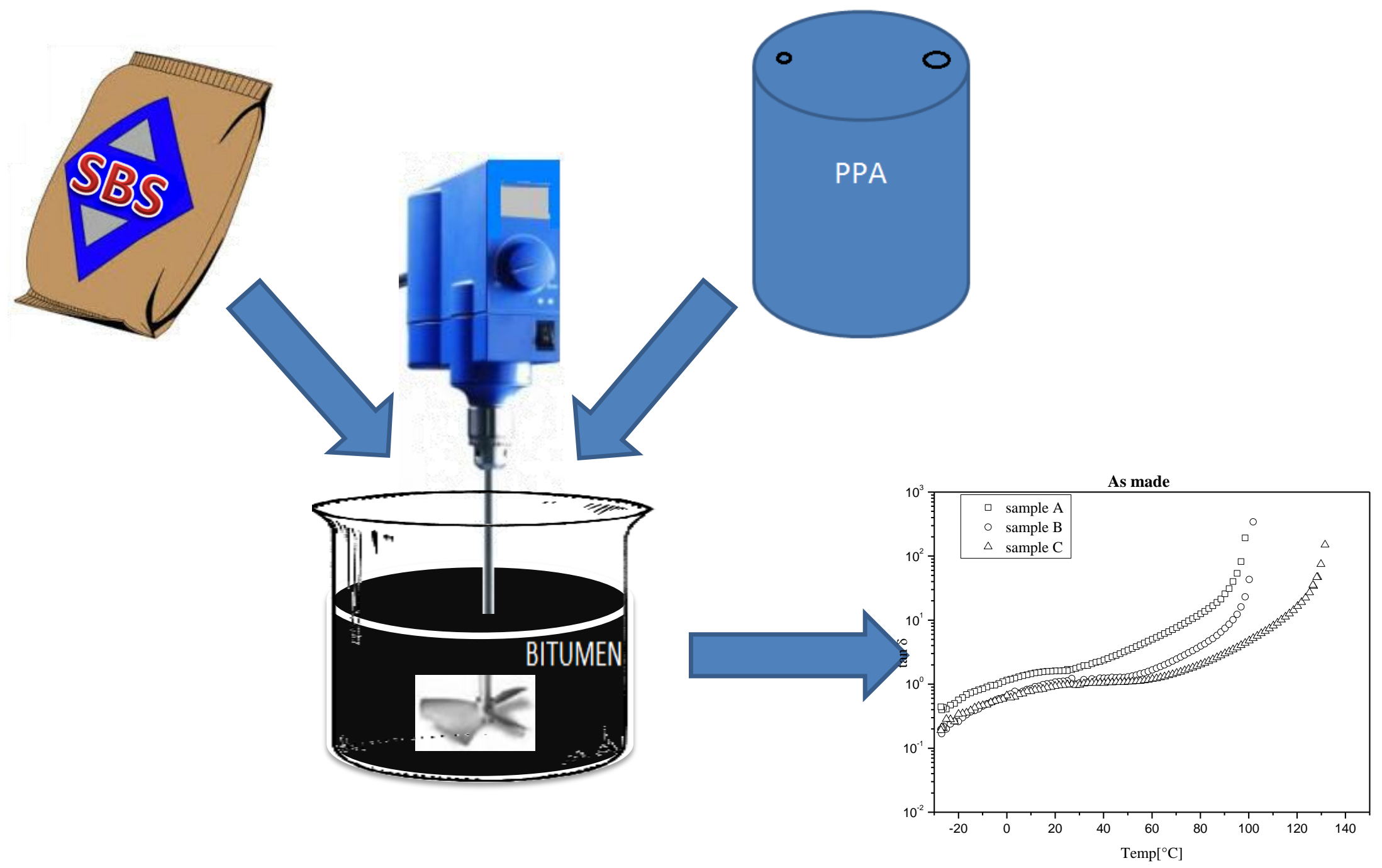



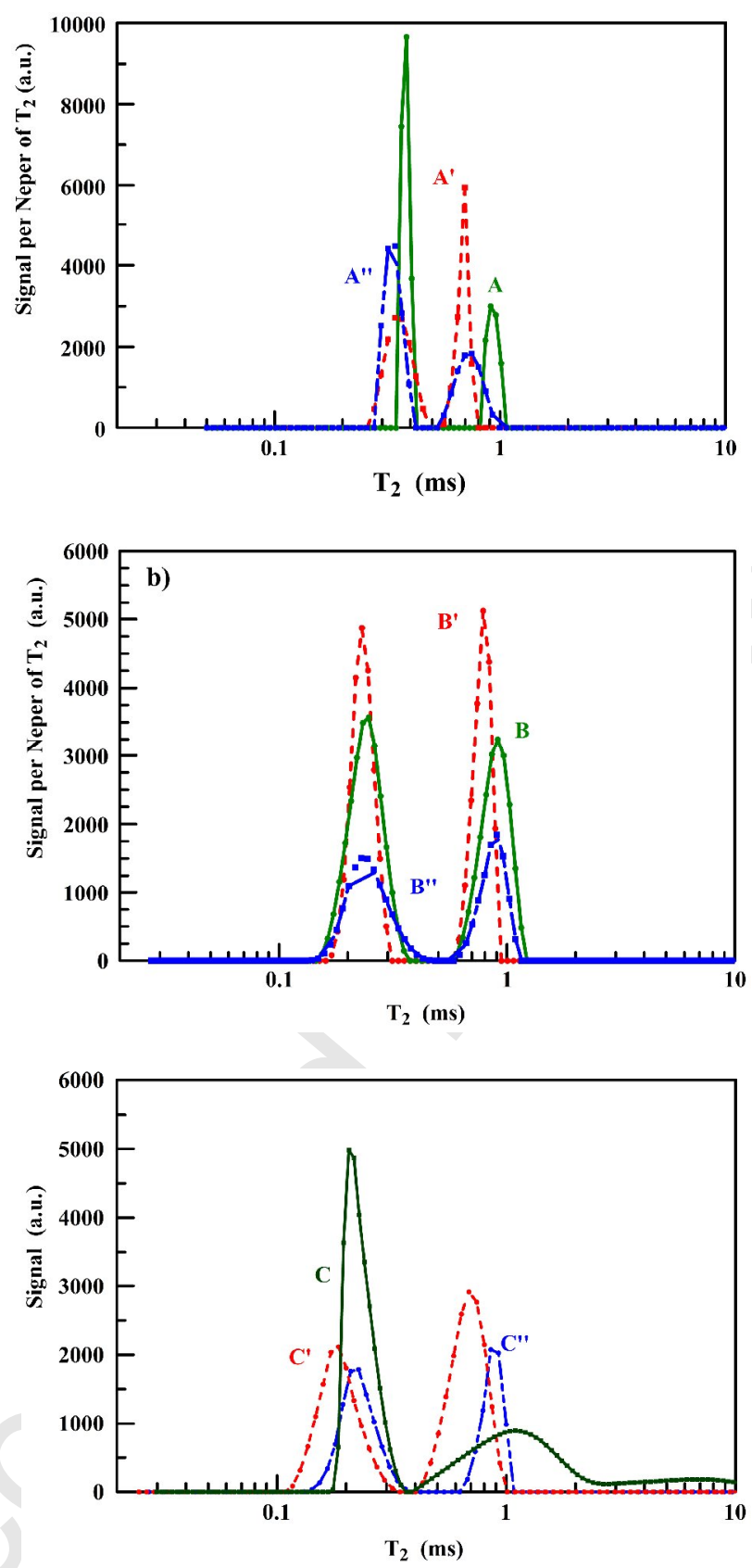

FIGURE 5 